\title{
O SUSSURRO COMO LINGUAGEM DA DENÚNCIA DE VIOLÊNCIA SEXUAL: UMA PESQUISA COM EDUCADORES DE CRECHE
}

\section{ITHE WHISPER AS LANGUAGE OF THE DENUNCIATION OF SEXUAL VIOLENCE: A SURVEY WITH NURSERY EDUCATORS}

\author{
Cristiano Rodineli de Almeida ${ }^{1}$
}

Submetido em: 31/12/2019

Correções requeridas em: 28/04/2020

Aprovado em: 14/09/2020

\section{RESUMO}

Neste trabalho apresentamos parte dos resultados obtidos em uma pesquisa de mestrado ${ }^{2}$ que se debruçou sobre o possível dilema da denúncia vivido pelo educador de creche frente a indícios de violência sexual contra crianças que frequentam a escola. Tendo como norte a pesquisa em psicanálise, entrevistamos cinco educadores de uma creche localizada em um município da grande São Paulo, buscando compreender como pensam e subjetivam as experiências ligadas à violência sexual perpetrada contra as crianças que frequentam a creche e como lidam com o aspecto formal da denúncia. Algo de um mal-estar emergiu nos discursos dos educadores ligado a interdição da fala sobre o fenômeno da violência sexual, encontrando somente o sussurro como possibilidade de articulação pela linguagem.

PALAVRAS-CHAVE: Educação infantil. Denúncia. Mal-estar Educacional. Psicanálise. Violência sexual.

\section{ABSTRACT}

In this paper, we present part of the results obtained in a master's research that focused on the possible dilemma of the denunciation experienced by the daycare educator facing evidence of sexual violence against children who attend school. Based on psychoanalysis research, we interviewed five educators from a day care center located in a city of Greater São Paulo, seeking to understand how they think and subjective experiences related to sexual violence against children attending day care and how they deal with the formal aspect of the complaint. Something of an uneasiness emerged in the educators' discourse linked to the interdiction of speech about the phenomenon of sexual violence, finding only whisper as a possibility of articulation by language.

KEYWORDS: Child education. Denunciation. Educational malaise. Psychoanalysis, Sexual violence

\footnotetext{
${ }^{1}$ Psicólogo clínico de orientação psicanalítica. Mestre em Educação e Saúde na Infância e na Adolescência, especialista em Psicopatologia e Saúde Pública e em Políticas Públicas e Socioeducação. Trabalha como psicólogo na Fundação CASA, atendendo adolescentes privados de liberdade. http://buscatextual.cnpq.br/buscatextual/visualizacv.do?id=K4249009U8. Correio eletrônico: cris.rondinelli@gmail.com

2 Pesquisa de mestrado intitulada: Os educadores de creche e a violência sexual infantil: um tema interditado, realizada no programa de Pós-graduação de Educação e Saúde na Infância e na Adolescência pela Universidade Federal de São Paulo.
} 


\section{INTRODUÇÃO}

Os fatos são sonoros, mas entre os fatos há um sussurro.

É o sussurro que me impressiona

(LISPECTOR, 1977, p. 39).

Quando falamos de violência, logo surge a ideia de uma relação entre a vítima, aquele sujeito que sofre, e o vitimizador, aquele que faz alguém sofrer. No entanto, é possível que outras pessoas se apresentem vinculadas a essa relação, como familiares, vizinhos e amigos. Mas, nem sempre essas pessoas são as primeiras a "saber" de uma situação de violência, pois, muitas vezes, ela é permeada pelo silenciamento e pelo abafamento de muros, janelas e portas cerradas. A partir das experiências do autor ${ }^{3}$, constatou-se que, frequentemente, situações de violência contra essa população se fazem presentes no interior de um espaço sui generis. Mesmo distantes do ambiente doméstico, do dia a dia das famílias e do seu entorno, crianças podem fazer "aparecer" as marcas da violência doméstica no interior do ambiente escolar da creche.

Nesse espaço singular, por meio da figura de seus educadores, torna-se possível o reconhecimento de situações de violência contra crianças. Indicadores físicos, como hematomas ou edemas, hemorragia vaginal ou retal, dificuldades em andar ou sentar, relatos de dor nos genitais, bem como os indicadores psicológicos, como mudanças ou regressão do comportamento, agressividade ou apatia, interesse súbito e incomum por questões sexuais, podem trazer a suspeita de que a criança possa ter sido ou estar sendo vítima de violência sexual (MOURA, 2008).

Embora seja percebida como um dos aspectos centrais no combate à violência, vale ressaltar que uma denúncia ${ }^{4}$ nem sempre se apresenta de forma verbalizada e consciente, podendo se mostrar por meio de uma espécie de "rastro" que indique sua ocorrência. Além das marcas no próprio corpo, seus sinais aparecem nos espaços onde se dão seus movimentos, na maneira como as crianças se comunicam e nas mais diversas formas de expressão pela linguagem. Esse conteúdo não totalmente revelado, mas possivelmente revelador e permeado pela dor daquilo que não pôde encontrar as vias de acesso à simbolização, engendra, muitas vezes, sentimentos de ambivalência e medo. É do reflexo desses sentimentos que tomam o corpo e o espaço da escola que emerge um mal-estar que tem o poder de acessar o educador. A esse fenômeno, a psicanálise denomina "transferência".

Entende-se esse fenômeno como a manifestação de conteúdos inconscientes provenientes de outras representações que são repetidas e atualizadas em relações do sujeito, as quais podem não apresentar semelhanças direta ou consciente com o conteúdo deslocado, mas que de algum modo conserva elementos inconscientes que permitem 0 investimento desse sujeito e, desse modo, que a transferência se instaure (FREUD, 1900/1996).

A transferência não ocorre somente no espaço de manejo terapêutico, ela está para o campo das relações da vida cotidiana na medida em que o inconsciente está presente nas mais diversas manifestações humanas (ROSA, 2016). Nesse sentido, a transferência também ocorre no ambiente escolar, no interior da relação alunoprofessor, em que o educador passa a ter uma função que serve de apoio para a transferência da criança que Ihe investe afetos e conflitos, de modo que o educador representa figuras parentais e demais pessoas significativas, ocupando lugares de saber e poder por meio da identificação (NUNES, 2004).

$\mathrm{Na}$ medida em que existe uma dialética situada

\footnotetext{
${ }^{3}$ O preâmbulo deste texto se baseia na experiência do autor enquanto psicólogo no campo das violências, nas áreas da assistência social (entre os anos de 2010 -13 foi representante do Polo de enfrentamento à violência do Distrito Jaraguá, supervisionado pelo Instituto Sedes Sapientiae - cidade de São Paulo), em consultório particular, no âmbito das Medidas Socioeducativas de privação de liberdade (desde o ano de 2013 atende adolescentes de ambos os gêneros acautelados na Fundação CASA/SP), e enquanto coordenador do Projeto Vagalume (desde 2015), o qual tem como objetivo criar espaços de discussão entre profissionais sobre o fenômeno da violência sexual contra crianças e adolescentes.

${ }^{4} \mathrm{O}$ emprego do termo "denúncia" é utilizado ao longo deste texto para se referir ao pedido de socorro (verbalizado ou não) realizado pela vítima, seja ela a criança supostamente violentada ou o educador frente suas angústias suscitadas pela temática. No âmbito jurídico, o ato formal de comunicar uma suspeita de violência assume o nome de notificação. Nesse contexto formal, a denúncia cabe ao Ministério Público.
} 
entre o educador e a criança que sofreu ou vive situações de violência sexual, há um mal-estar nessa relação fruto não somente da violência em si mesma e da necessidade legal de se fazer a notificação de violência, mas também pela subjetividade do educador, suas histórias de vida e diferentes concepções sobre o próprio tema da violência sexual que transcendem o aspecto da necessidade imperiosa da denúncia pura e simplesmente, como um procedimento inerente à função social do educador (ALMEIDA, 2017).

Apesar da obrigação imposta pela legislação para a efetivação da denúncia, tal como descrito no artigo 245 do Estatuto da Criança e do Adolescente: "Deixar o médico, professor ou responsável por estabelecimento de atenção à saúde e de ensino fundamental, pré-escola ou creche, de comunicar à autoridade competente os casos de que tenha conhecimento, envolvendo suspeita ou confirmação de maus tratos contra criança ou adolescente", é possível que fatores culturais e a própria subjetividade do educador estejam presentes nessa relação. Assim, o educador de creche pode se posicionar em meio ao conflito entre o discurso social e seu mito individual - suas crenças, valores morais, vivências e, sobretudo, as marcas inconscientes que envolvem singularmente sua relação com o tema -, identificando-se e projetando-se na situação.

É nesse sentido que nos propomos a discutir um dos resultados que surgiram ao longo de uma pesquisa de Mestrado desenvolvida na Universidade Federal de São Paulo, condizente a linguagem do sussurro utilizada pelos educadores ao tratarem sobre o tema da violência sexual. Os atravessamentos da temática da violência sexual, tanto de ordem subjetiva quanto objetiva, possibilitam a instauração de um mal-estar no ambiente da escola. Percebemos a existência desse mal-estar pelo que emergiu no discurso dos sujeitos entrevistados: a interdição da fala manifestada pela linguagem do sussurro.

\section{OBJETIVOS}

Tendo como lastro teórico a psicanálise freudiana, somada às discussões trazidas por alguns pósfreudianos, tomamos como objetivo principal de nossa pesquisa de Mestrado a investigação de um suposto mal-estar existente entre os educadores de creche em decorrência da percepção de indícios de violência. Em outras palavras, gostaríamos de saber como aqueles educadores pensavam e subjetivavam as experiências ligadas à suposição ou constatação de uma situação de violência sexual perpetrada contra as crianças que frequentam a creche - conforme a legislação brasileira, crianças entre zero e três anos de idade (PORTAL BRASIL, 2014) - e como lidam com o aspecto formal da notificação nos casos de ameaça e confirmação de violência contra essas crianças, conforme diretriz estabelecida pelo Estatuto da Criança e do Adolescente (ECA) (Lei n. 8.069 de 1990).

No que tange o objetivo deste artigo, é discutir um dos resultados obtidos na pesquisa, condizente com a linguagem do sussurro trazida no discurso dos sujeitos entrevistados.

\section{MÉTODO}

O desenvolvimento desta pesquisa teve como método a abordagem qualitativa, realizada a partir de entrevistas com cinco educadores de creches acerca da temática da violência sexual e do aspecto da denúncia desses casos. Esses profissionais da educação infantil compunham a rede pública de ensino em um município da região da Grande São Paulo ${ }^{5}$.

Com o objetivo de privilegiar o sujeito na pesquisa, não apreendendo o educador meramente como um objeto de estudo, mas como parte fundamental e ativa do trabalho, propusemos a esses sujeitos a escolha de nomes fictícios que sinalizassem suas narrativas, como um passo "importante para introduzir a dimensão da memória" (GOMES, 2013, p. 92). A pesquisa em psicanálise implica, para além da produção de um saber, na possibilidade de transformação dos sujeitos que nela estão abarcados: pesquisador e pesquisado (MARIOTTO, 2009; ROSA, 2016). Desse modo, a seleção de nomes é permeada de intencionalidade: os sujeitos se dedicam a essa escolha como significante que perpassa as lacunas do tempo e do desejo inconscientes do sujeito, ao mesmo tempo em que trazem um aspecto mais informal e livre à emergência

\footnotetext{
${ }^{5}$ Por questões éticas firmadas com os sujeitos de pesquisa, além do sigilo de suas identidades, foram preservados também os nomes das escolas e município pesquisados.
} 
das narrativas. Assim, os que outrora eram chamados de sujeitos de pesquisa, deram lugar a: Clara, Lilian, Mirela, Nelson e Paula.

Em razão deste trabalho privilegiar a experiência singular do sujeito, sem a pretensão de oferecer generalizações, a quantidade de sujeitos que aderiram à pesquisa se mostrou adequada ao que pretendíamos investigar. Isso porque, em uma pesquisa qualitativa, não se considera a quantidade de entrevistas como sendo o mais importante, mas o conteúdo considerado suficiente para abordar adequadamente uma questão de pesquisa. Nesse sentido, apesar de estar fora do consultório particular, a escuta psicanalítica pode se dar em diferentes contextos, na medida em que se entende que $\mathrm{o}$ inconsciente está presente nas mais diversas manifestações humanas (ROSA, 2016).

Ao se debruçar sobre a investigação de fenômenos sociais, culturais e políticos, ao contrário das pesquisas que se amparam nos métodos positivistas de planejamento e controle da situação observada e de seus resultados, a psicanálise permite considerar que " o desejo do pesquisador faz parte da investigação e o objeto da pesquisa não é dado a priori, mas sim produzido na e pela investigação." (ROSA e DOMINGUES, 2010, p. 182).

Desse modo, a pesquisa em psicanálise leva em consideração a impossibilidade de neutralização e totalização do saber. Isto é, o pesquisador é parte da pesquisa, situa-se em uma relação com o que é pesquisado e sabe, de antemão, que não poderá nem terá como pretensão deter tudo sobre o que está pesquisando. Como observam as autoras, tanto o pesquisador quanto o sujeito da pesquisa ou os objetos (propriamente ditos) sob os quais se debruça, encontram-se no interior de uma relação sujeita a transformações de ambas as partes. É na relação com o sujeito da pesquisa - que a psicanálise considera como sendo o sujeito do inconsciente, do desejo - que se torna possível a construção de um saber. $\mathrm{O}$ acesso a esse saber que se localiza no sujeito pesquisado, dáse pela palavra, por meio da escuta do seu discurso (MARIOTTO, 2009).

A investigação de fenômenos sociais e políticos pelo enfoque psicanalítico, desde que se mantenha o pressuposto ético - condizente à escuta do sujeito do inconsciente -, pode contribuir "para a elucidação de sua eficácia no processo de alienação do sujeito e apontando os laços que possibilitem a sua inclusão como sujeitos do desejo" (ROSA, 2004, p. 340). Em outras palavras, uma pesquisa em psicanálise considera possível haver transformações no sujeito, oferecendo condições de elaboração psíquica e de mudança na posição subjetiva frente às questões abordadas em uma pesquisa. É por isso que Rosa (2016) prefere o termo psicanálise implicada, pois um psicanalista escuta os fenômenos transversais (sociais, econômicos e políticos) que atravessam a história do sujeito e demais determinantes que fazem parte de sua constituição subjetiva com a intenção de provocar mudanças na posição do sujeito. Assim, a pesquisa em psicanálise permite a escuta dos não-ditos de cada sujeito e, inclusive, da escuta dos "não-ditos dos enunciados sociais" que atravessam a subjetividade singular de cada um, possibilitando a emergência do sujeito do desejo (p.340).

Esse enfoque ético condiz com o que procuramos trazerneste trabalho, favorecendo com que, sem encaixes e sobreposições teóricas, o sujeito do inconsciente pudesse emergir na fala dos educadores de creche. Mas é preciso termos em mente que esse sujeito foi escutado levando em consideração as questões desta pesquisa e, portanto, não totalmente livres, apesar da liberdade de dizerem o que lhes viesse à mente sobre o assunto e, até mesmo, na possibilidade de não falar sobre as questões desta pesquisa extramuros.

É nesse mesmo sentido que o emprego do questionário - que condiz com o modelo das entrevistas semidirigidas - poderia se apresentar como empecilho à proposta de investigação pelo viés psicanalítico. Buscamos dar conta desse risco ao utilizarmos o questionário como delimitador do tema de nossa investigação, mas não nos limitando a ele na escuta dos sujeitos de pesquisa. Por isso consideramos as questões disparadoras apenas um ensejo para o estabelecimento de um diálogo entre pesquisador e educador, distanciando-nos da objetividade dos roteiros pergunta-resposta.

\section{RESULTADOS E DISCUSSÃO}

O sussurro, modelo de linguagem adotado por quem fala algo que precisa ser mantido em segredo, era comum entre os educadores entrevistados. Pareceunos que $o$ assunto da violência sexual contra crianças assumia naquele espaço a ordem de uma fala proibida. 
Não se tratava de um procedimento combinado entre o grupo de profissionais ao se depararem com tais situações, tampouco decorrente de alguma orientação da gestão escolar, dos manuais educativos ou da legislação vigente. Tratava-se, portanto, de um acordo tácito, algo não expresso de maneira formal, mas existente naquelas relações, algo da ordem do tabu.

Os educadores, na situação das entrevistas, ao tocar em algum assunto referente à violência sexual (dos sinais percebidos em crianças, de seus próprios sentimentos e com relação à denúncia) abaixavam o volume de suas vozes. Entrávamos, desse modo, em um campo da linguagem no qual a compreensão do falado se completava na leitura labial e no tom da voz. Pode-se depreender algo do simbólico interditado que parecia surgir nesses momentos, como se a fala tocasse em pontos impronunciáveis, onde a palavra não circula ou não pode circular. Assim, naquele momento a linguagem tomava a forma de "um sussurro siderante. $O$ ar que abre um caminho parece modular as palavras do impossível de dizer, à maneira de uma expiração. Alento rouco que retém o grito e o elude" (HASSOUN, 2010, p. 94).

Imersos nesses sussurros existiam pedidos de ajuda e orientação envoltos em relatos de desabafo e revolta, tal como na fala de Lilian:

[...] você não ter certeza que está acontecendo, porque ninguém sabe o que acontece na casa de uma criança. Essa dúvida traz sofrimento porque se realmente tá acontecendo e a criança tá sofrendo o que eu faço? A criança precisa de você e você não tem certeza de nada. Acho que é essa incerteza que impede com que as pessoas façam a denúncia, se você levanta a suspeita você tem que provar, e aí como você fica?

Ao abordar a questão da denúncia na creche, a busca dos educadores pela verdade material da violência, ou seja, por encontrar provas que sinalizem sua ocorrência de fato, acaba ensejando um caminho solitário, na medida em que percebe que não pode ou deve compartilhar as inquietações contidas em suas conjecturas. Por ser considerado um assunto "delicado", pertencente ao campo do tabu, o tema da violência sexual tem seus espaços de fala e discussão reduzidos.
Pareceu-nos que, diante da impossibilidade da livre circulação das palavras, aqueles sujeitos encontraram no espaço das entrevistas desta pesquisa brechas que possibilitaram o estabelecimento de uma escuta.

Ao sussurrar uma denúncia, o educador buscava dar conta de algo que lhe causava medo, raiva ou angústia, mas que, talvez, não encontrasse escuta e espaços necessários para compartilhar esses sussurros. Esses educadores não encontravam quem pudesse escutálos em sua relação transferencial com as questões suscitadas no dia a dia profissional/e, especialmente, com relação aos impasses oriundos da violência sexual:

\section{[...] a sensação que vem dentro de você é uma angústia muito grande. Você quer resolver isso de imediato, você vai dormir, você lembra daquilo, mas muitas vezes você não pode resolver de imediato (CLARA).}

Nesse território de impasses, no que compete ao desejo de saber sobre o que fazer diante das suspeitas de violência sexual, surge entre os educadores uma vontade de investigar, de extrair uma verdade que, antes de tudo, pudesse dissolver as próprias angústias criadas na relação com a possível cena da violência sexual. Contudo, essa vontade resvalava na insegurança e no desejo de que aquilo não se apresentasse enquanto verdade:

[...] eu sempre quero saber o que aconteceu, porque a gente não sabe realmente o que aconteceu, aquela coisa de investigar, por mais que senti raiva, o primeiro sentimento é raiva, o segundo é deixa ver o que aconteceu, às vezes o nosso olhar engana, às vezes eu fico pensando que aconteceu alguma coisa mais grave com a criança e não é. (PAULA)

Em razão da violência sexual por vezes deixar poucos sinais concretos e visíveis, a busca de Paula é por uma confirmação que está além de seu alcance. O nebuloso campo da violência sexual, permeado pelo impedimento da fala, por incertezas e angústias suscitadas pela temática, assumia corpo de um animus denunciandi, ou "denuncismo" entre os educadores (RIBEIRO, 2001). Esse denuncismo estava presente 
nas entrevistas não no sentido da realização da denúncia propriamente dita, mas de um movimento de ideias persecutórias que se apresentavam no imaginário dos educadores como ameaças e perigos reais. Desse modo, a palavra "será", utilizada diante da suspeita de violência sexual, repetiu-se no discurso dos educadores, como significante da dúvida e da falta de um saber que pudesse dar conta da situação. Esse significante nos remete a um pedido de ajuda diante do imbróglio suscitado pelas suspeitas de violência sexual contra crianças no ambiente de trabalho.

$\mathrm{Na}$ prática, os educadores relataram que ao notarem indícios de violência em suas crianças, parte de suas inquietações eram mantidas em silêncio, mas havia um incessante desconforto subjetivo. Indagações surgiam em uma tentativa de planejamento racional que antecedia à tomada de uma decisão. Esses questionamentos, para além da objetividade do raciocínio, estavam permeados por questões de ordem subjetiva que traziam à cena psíquica conteúdos da própria vivência do educador: suas histórias, experiências, dores e alegrias confundiam-se com a cena do "agora", a cena da criança/aluno supostamente marcado pela violência. Havia, portanto, uma relação transferencial na relação educador-aluno, marcada pela identificação com a vítima ou, por vezes, tal como dito por Ferenczi (1932/2006), uma identificação com a culpa do agressor, tal como trazido por Mirela:

Eu sofri muito porque me senti incapaz. Eu absorvi tudo aquilo como se eu fosse culpada do que a criança estava vivendo. Por me sentir incapaz, por ser uma mulher e não ter condição de ajudar essa criança, por ninguém me ouvir.

A identificação com a culpa do agressor se apresentou como importante elemento nos discursos dos educadores ao tratarem sobre seus dilemas com a denúncia. A falta de simbolização pode levar a criança violentada a imbuir a culpa a si mesma, justamente por não encontrar recursos subjetivos e objetivos que justifiquem a violência sofrida. A própria fala do agressor pode favorecer essa identificação, no que tange as ameaças a si mesma e a outros representantes da família, colocando a criança no lugar de responsável por uma conjuntura complexa, ao passo que "o adulto sedutor assume atitudes superegóicas, pedagógicas e, inclusive, hipocritamente moralistas" (CABRÉ, 2006, p. 48). Nesse quesito, Cromberg (2012) aponta como importante propulsor dessa identificação a falta de espaços de escuta e de confiança, seja na família ou nas instituições que validem a fala e os não-ditos da criança e a reconheça como vítima, não a revitimizando ao assumirem uma posição dúbia. Frequentemente, o não reconhecimento e a descrença leva a vítima a se reconhecer como a culpada da história: culpada inconscientemente pela agressão, pela violação da lei do incesto e pela suposta perda do amor do pai (ou qualquer outro representante) simbólico e demais efeitos que a denúncia poderia trazer a essa família e ao próprio denunciante.

Outro ponto ligado aos resultados da pesquisa e que acabava por intensificar o mal-estar já circulava entre aqueles profissionais foi a presença de um homem na rotina de trabalho direta com as crianças. As educadoras não trouxeram elementos acerca desse ponto, contudo, o educador entrevistado narrou seu desconforto com a temática e com um suposto lugar ocupado perante o olhar do outro. Nelson, ao aventurarse em um campo de trabalho tradicionalmente ocupado por mulheres, percebe que causa desconfianças nas colegas de trabalho.

[...] na hora do banho, é muito difícil eu dar um banho, não que eu não me ofereça, mas sempre tem alguém que pula na frente pra dar banho ou pra trocar. Por mim tá ótimo, é menos trabalho, mas fico meio... Não tem lugar nenhum que tá escrito isso, tem que desenvolver a mesma função.

Pensamos que sua própria condição de gênero o implica numa desconfiança dos olhares femininos, pois, ao longo da história da humanidade, seu sexo promoveu relações assimétricas de poder em que o masculino se sobrepôs ao feminino pela utilização das violências psicológica, física (inclusive, a sexual), além da social por meio de discriminação e exclusão. Desse modo, possivelmente Nelson acaba sendo representado no imaginário das educadoras como uma ameaça, ocupando o lugar do homem, com todo seu lastro histórico e social, e fadado a replicá-lo em suas próprias relações com as crianças e mulheres com quem trabalha 
na creche.

Nesse lugar de desconforto, Nelson evita algumas atividades justamente por saber que sua condição de homem, imerso em um universo tradicionalmente feminino e no cuidado de crianças pequenas, possa parecer ao outro como algo ameaçador:

[...] às vezes você percebe uma menina com um problema de assadura e você é obrigado a falar pro pai quando ele vem buscar e você percebe no pai meio que uma coisa assim: "é, pô, o cara foi ver se minha filha tava assada!". Então você é obrigado a pedir pra educadora ir lá falar e você fica sempre atrás. Esse tipo de coisa eu não gosto, acho que tem que ser por igual, por que eu não posso falar que a menina tá com uma assadura, não é? Apesar de já ter pai que já conversou comigo sobre isso de boa, tipo uma das meninas tava com problema vaginal e tinha que passar uma pomada específica bem na vagina mesmo, ele falou comigo e eu falei: "obrigado pela confiança”, não falei isso, mas senti.

Pareceu-nos que Nelson, ao trazer esse relato, ocupava um lugar de "evitação", um costume adotado por algumas culturas primitivas que buscavam regular as relações, limitando os contatos entre homens e mulheres - em sua maioria ligados à possibilidade do incesto, como entre pai e filha, mãe e filho, irmão e irmã, primo e prima e entre genro e sogra - a fim de evitar um possível ato sexual, como se fosse uma decorrência necessária que o "encontro a sós entre um homem e uma mulher conduz naturalmente a uma intimidade imprópria entre eles" (FREUD, 1905/2006, p. 30).

O acordo tácito em que Nelson se insere rege-se por uma ordem social em que o homem é visto como alguém dotado e regido por um lugar privilegiado de poder em suas relações com o outro, em especial o outro feminino. É como se o homem fosse portador de uma maldição que teimasse em se realizar pela ordem do abuso e do incesto. Assim, o homem-educador, responsável pelo cuidado de crianças pequenas, passa a ser, tal como a própria temática da violência sexual, também permeado pelo tabu.

\section{CONSIDERAÇÕES FINAIS}

O processo psicanalítico se dá pela fala de um e a escuta de outro numa relação transferencial que possibilita o afetar (no sentido da possibilidade de transformação) dos sujeitos envolvidos (CROMBERG, 2012). Assim, o pesquisador também pode ser "afetado" por esse encontro e por suas possibilidades de construção de um saber a partir das narrativas dos sujeitos. Falamos aqui de nossa experiência na pesquisa, a qual foi marcada inicialmente pela mudança de perspectiva em relação à denúncia de violência sexual. De início, nossa concepção estava assentada em um saber mais voltado ao campo do Direito e, portanto, das regras, procedimentos e normas que deveriam regular a sociedade e o fazer nesse campo. Acreditávamos, equivocadamente, que a questão da violência sexual tinha como lastro a lei jurídica. Incomodávamos com a ineficiência dos mecanismos de denúncia e, sobretudo, com a ineficácia dos denunciadores (entre eles os educadores) diante de suspeitas de violência sexual.

Assim, inseríamos esta pesquisa em um discurso às voltas com protocolos que buscavam descrever objetivamente esse fenômeno: Violência sexual é... Esse tipo de violência pode causar... Para denunciar ligue no Disque 100, procure a Delegacia de Polícia ou Conselho Tutelar mais próximo.

Essa ideia começou a ruir com o caminhar da pesquisa, das leituras e as discussões que se seguiram até o culminar de nosso encontro com os educadores. Nesses encontros, percebemos a existência de um mal-estar no ambiente de trabalho dos profissionais, algo que não se esgotava em explicações jurídicas ou nos manuais de orientação. A violência sexual contra crianças, sobretudo a incestuosa, está assentada no campo do tabu devido à ambivalência subjetiva que tangencia esse tema. A aproximação com o tabu, como referido por Freud (1913/2006), é percebida pela sociedade como algo da ordem do impuro. Assim, o próprio ato de denunciar pode levar o sujeito a esse lugar, tornando o denunciante impuro e, desse modo, digno de ameaças de represália pela sociedade. Como os aparatos da denúncia não se mostravam suficientes para dar conta do que o educador vivenciava em sua relação com o tema da violência sexual, a denúncia passava a ser vivida como um dilema.

Percebemos que, embora existam obrigações 
legais para a realização da denúncia, prevaleciam aspectos de ordem mais profunda, marcados pela relação transferencial daqueles profissionais com o fenômeno da violência sexual contra crianças. A cena percebida entre seus alunos que, de alguma forma, levantava a suspeita da ocorrência de violência sexual, remetia-os a outra cena - agora no psiquismo do educador ao mobilizar suas próprias marcas subjetivas que remetem às vicissitudes da sua própria constituição, envolvendo a dimensão do incesto e da proibição.

A denúncia não é algo meramente procedimental; ao contrário, está permeada por uma série de fatores para além do campo jurídico, ligados, por um lado, a questões culturais e históricas e, por outro, relacionadas a aspectos de ordem subjetiva, marcados por identificações, projeções e demais mecanismos inconscientes do sujeito em sua relação com a situação de violência e seus envolvidos. Para os educadores pesquisados, a denúncia era vivida como um dilema ético e moral, permeada por questões de ordem psicológica, cultural e sociológica, de maneira consciente e inconsciente. Disso depreende-se um possível sofrimento psíquico do educador em face dos aspectos que envolvem a denúncia, um sofrimento que se inscreve, desse modo, no campo de um mal-estar educacional.

\section{REFERÊNCIAS}

ALMEIDA, C. R. V. Os educadores de creche e a violência sexual: um tema interditado. 2017. Dissertação (Mestrado em Educação e Saúde na Infância e na Adolescência) - Escola de Filosofia, Letras e Ciências Humanas, Universidade Federal de São Paulo. Guarulhos, 2017.

CABRÉ, L. M. Sándor Ferenczi. A revalorização da teoria psicanalítica do trauma. Revista de Psicanálise da Sociedade Psicanalítica de Porto Alegre. Porto Alegre, v. 13, n. 1, p. 39-57, 2006.

CROMBERG, R. U. Cena Incestuosa: abuso e violência sexual. São Paulo: Casa do Psicólogo, 2012.

FERENCZI, S. (1932). A confusão de línguas entre os adultos e a criança: a linguagem da ternura e da paixão. Revista de psicanálise da sociedade psicanalítica de Porto Alegre. Porto Alegre, v. 13, n. 1, p.13-24, 2006.
FREUD, S. (1900 [1899]). A interpretação dos sonhos. In: FREUD, S. Edição Standard Brasileira das Obras Psicológicas Completas de Sigmund Freud (Vol. IV, pp. 13-363). Rio de Janeiro: Imago, 1996.

(1905). Três ensaios sobre a teoria da sexualidade. In: FREUD, S. Edição Standard Brasileira das Obras Psicológicas Completas de Sigmund Freud (Vol. VII, pp. 117-229). Rio de Janeiro: Imago, 2006.

GOMES, Marineide O. Formação de professores na Educação Infantil. São Paulo: Cortez, 2013.

LISPECTOR, C. A hora da estrela. Petrópolis: Rocco, 1977.

MARIOTTO, R. M. M. Cuidar, educar e prevenir: as funções da creche na subjetividade de bebês. São Paulo: Escuta, 2009.

MOURA, A. C. M.; SODELARIO, A. S.; CAMARGO, C.N.M.F.;FERRARI, D.C.A.; MATTOS, G.O.; MIYAHARA, R. P. Reconstrução de Vidas: como previnir e enfrentar a violência doméstica e a exploração sexual de crianças e adolescentes. São Paulo: SMADS/ Sedes Sapientiae, 2008.

NUNES, M. R. M. Psicanálise e educação: pensando a relação professor-aluno a partir do conceito de transferência. In: COLÓQUIO DO LEPSI/IP/FE-USP. 2004. São Paulo. Anais. Disponível em: http://www. proceedings.scielo. br/scielo. php?pid=MSC00000000 32004000100040 \&script=sci arttext\&tlng=pt. Acesso em: 15 dez. 2016.

PORTAL BRASIL. Educação. Saiba como funciona o sistema de educação infantil no país. 2014. Disponível em: http://www.brasil.gov.br/educacao/2012/04/creche. Acesso em: 15 dez. 2016.

RIBEIRO, Alex. O caso da escola base: os abusos da imprensa. São Paulo: Ática, 2001.

ROSA, M. D. A clínica psicanalítica em face da dimensão sociopolítica do sofrimento. São Paulo: Escuta/ Fapesp, 2016. 


\section{rejvista educação}

O SUSSURRO COMO LINGUAGEM DA DENÚNCIA DE VIOLÊNCIA SEXUAL: UMA PESQUISA COM EDUCADORES DE CRECHE

ROSA, Miriam D. \& DOMINGUES, Eliane. O método na pesquisa de fenômenos sociais e políticos: a utilização da entrevista e da observação. Psicologia \& Sociedade, Porto Alegre, v. 22, n. 01, p. 180-188, 2010.

ROSA, Miriam D. A pesquisa psicanalítica dos fenômenos sociais e políticos: metodologia e fundamentação teórica. Revista mal-estar e subjetividade, Fortaleza, v. 4, n. 2, p. 329-348, 2004. 